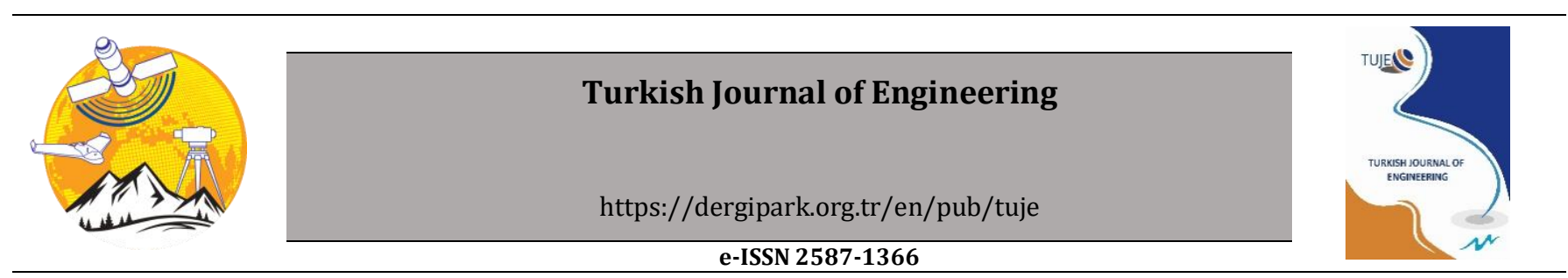

\title{
Repairing of damaged composite materials and self-healing composites
}

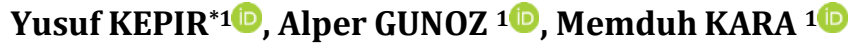 \\ ${ }_{1}^{1}$ Mersin University, Department of Mechanical Engineering, Mersin, Turkey
}

\author{
Keywords \\ Self-healing composites \\ Microcapsule \\ Repair of composites \\ Patch \\ Intelligent materials
}

\begin{abstract}
Repairing any damage in composite materials is very important in terms of the mechanical strength of the structure in which they are used. Therefore, the damage needs to be detected and repaired quickly. The increasing use of composite materials in various industries makes it more important to repair damage in composites both quickly and cost effectively. Patch repair method is one of the most preferred methods for repairing damaged composites because it does not create a new tension on the structure it is applied, does not damage the damaged area and is light. In addition, thanks to the embedded microcapsules placed in its matrix, self-healing composites have been studied in recent years. In this study, both the repair of composite materials and self-healing composites are discussed.
\end{abstract}

\section{INTRODUCTION}

The use of polymers and polymer-based composites in structural applications in aircraft, cars, ships, defense and construction industries is increasing day by day. Despite their superior properties, composite materials used in many areas today can be damaged over time due to the stresses and loads they are exposed to. Replacing the damaged item is both costly and time consuming in terms of procuring the material. Instead, repairing the damage to the material is the most reasonable solution in terms of both cost and time. Various techniques have been developed and adopted to repair visible or detectable damage on polymeric structures $\mathrm{CWu}$ et al. 2008). Damaged composite structures can be repaired by methods such as patching and bonding. The repaired material is in many cases stronger than before it was damaged. Considering the spare part supply time, labor, part and replacement costs, it is often preferred to repair damaged composite materials because it is very advantageous (Adin 2018).

There are three types of repairs, depending on the size of the damage area (Abrate 1998). These are superficial repair, temporary repair and structural repair. Superficial repair methods are used in cases where damage to the material does not affect the structural integrity of the material. Temporary repair methods are used in cases where the damage does not threaten the structural integrity and mechanical properties of the material itself. Simple patch repairs can be given as an example of the temporary repair method. For example, screwed aluminum plate or riveted fiberreinforced patches are some of the temporary repair methods. The large damage area in the material can only be repaired by structural repair. Among the structural repair applications, the patch repair method is widely used.

Repair of the damaged sample is usually carried out with external reinforcement parts. With the development of technology in recent years, the focus of scientific studies has been directed to micro and nanoscale studies. Scientists have focused their studies on composite materials that can repair themselves. These materials can repair themselves in case of damage thanks to the micro and nanoscale capsules placed inside while they are being produced. In case of damage, certain triggering conditions are provided, allowing the capsules to break down and thus the repair process to begin. When the trigger condition is realized, the alkyd resin that comes out with the breakdown of the capsules penetrates the damaged area and performs the repair.

In this study, information about repair of damaged composites and self-healing composites are discussed.

\section{REPAIR OF DAMAGED COMPOSITES}

It is a common problem that composites exposed to mechanical, chemical, thermal, etc. stresses are damaged over time. There are various types of damage such as

\footnotetext{
* Corresponding Author

*(ykepir@mersin.edu.tr) ORCID ID 0000-0002-3536-3931

(alpergunoz@mersin.edu.tr) ORCID ID 0000-0001-7978-6306

(memduhkara@mersin.edu.tr) ORCID ID 0000-0002-5201-5453 
matrix damage, delamination, and fiber damage. These damage types are shown in Figure 1.

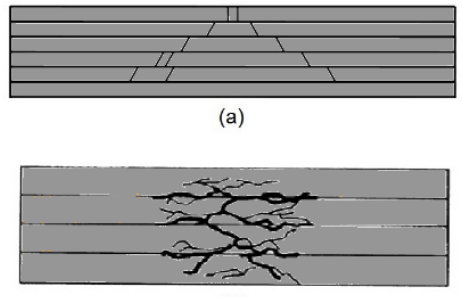

(b)

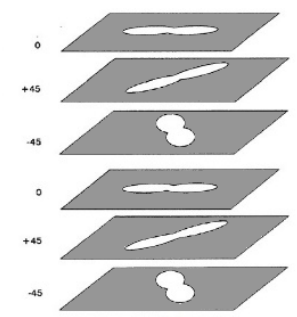

(c)
Figure 1. (a)Matrix damage (b)Fiber damage (c) Delamination (Kara 2012)

Damage to the material can be visible or detected by non-destructive testing methods. All types of damage that occur reduce the strength of the material and pose a threat to the security of the building to which it belongs.

Repair methods are used to extend the life of damaged or manufacturing defective components of various structures. Fatigue recovery, crack closure and corrosion repair are among the main objectives of repair (Dağdelen 2010).

The repair of the damaged composite structure takes place in three stages: structural damage assessment, repair design and analysis. If these three stages are successfully overcome, the composite structure becomes ready for long-term use (Kara 2012).

There are some basic repair methods used during the repair of a damaged composite structure. These methods are classified as superficial repair, temporary repair and structural repair. As superficial and temporary repair methods; Protective tape method, resin sealing method, filling repair method, repair method with bolted pairs can be given as examples. Hand lay-up method, pre-preg repair method and patch repair method can be given as examples of structural repair methods (Kılınç 2019).

It is the most preferred patch repair method among the above mentioned repair methods. The patch repair method can be used in two ways, as filling and stepped patch repair. Filling patches are a method of patch repair that requires good bonding strength and is used on flat parts. Figure 2 shows a schematic representation of the filling patch method.
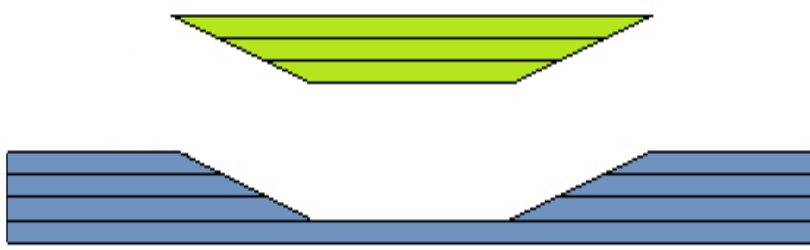

Figure 2. Filling patch method (Dağdelen 2010)

The other method of patch repair, stepped patch repair, is used in applications where it is necessary to minimize composite layers that take up extra space. It has two different types as single-sided and double-sided step patch. A schematic representation of the singlesided stepped patch repair method is presented in Figure 3.
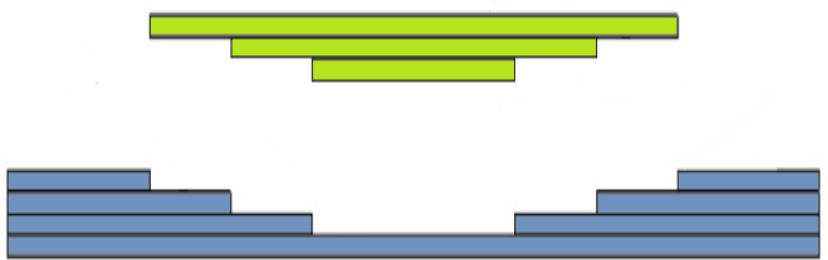

Figure 3. Single-sided step patch method (Dağdelen 2010)

The most preferred of the repair methods that can be made to the damaged area of the material is to create double-sided overlapping joints with a fiber-reinforced composite patch. The material is repaired by applying the adhesively bonded patch to the damaged area. The double-sided stepped patch repair method is given in Figure 4.

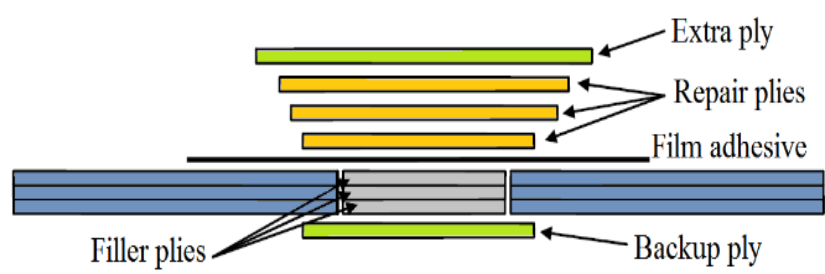

Figure 4. Patch repair application for layered composites (Kara 2012)

The advantages of adhesive bonds can be listed as follows;

- It can be easily applied to materials of different thicknesses.

- These connections also act as seals.

- Good insulation and damping abilities.

- They are easy and cheap connection forms.

- No stress accumulation since they do not damage the structure of the elements to be connected to each other (Erkek 2019).

There are studies in the literature on the repair of damaged composites and various patch methods.

Li et al. (2019) in their study, produced many carbon fiber / epoxy composite plates with holes of the same size and repaired these plates with patches in various geometries. They subjected the patch repaired samples and the undamaged base sample to tensile testing. As a result of the study, it was concluded that the tensile strength of the samples repaired with patches improved between $5 \%$ and $16 \%$ compared to the non-damaged sample, depending on the patch shape.

He et al. (2019), in their study, repaired the damaged aluminum alloy plates using carbon fiber reinforced epoxy resin composite patches. As a result of their performance evaluation of the mechanical properties of damaged sheets repaired with a two-layer carbon fiber/epoxy composite patch, they concluded that the repair efficiency of repaired aluminum alloys increased to $160 \%$ compared to undamaged aluminum alloys.

Kim et al. (2020) produced polyvinyl chloride (PVC) sandwich composites with the resin transfer method in their study. They subjected these samples they produced to bending and fatigue tests. They repaired the damaged samples with 3 different patch types: scarf patch, step patch and external patch. They subjected the repaired specimens to re-bending and buckling tests. As a result of 
the tests performed, they showed that the sample repaired with the scarf patch had a recovery rate of approximately $92 \%$.

Moreira et al. (2020) investigated the repair efficiency of 5 different patch types, namely Single-Strap, Double-Strap, Scarf, One-Stepped and Two-Stepped, on the damaged carbon-epoxy composite plate in their numerical study. They performed numerical fatigue and 3 point bending experiments by modeling the samples separately with different patch types. As a result of the study, they observed the bending and fatigue strength of the repaired samples with two stepped patch as $141 \%$ and $94 \%$, respectively.

Psarras et al. (2020) investigated the effect of repair of carbon fiber reinforced polymer composites (CFRP) with scarf patch on the mechanical properties of the sample. They subjected the CFRP sample to tensile testing. They repaired the damaged sample with a scarf patch. They observed the tensile strength recovered in the repaired sample as $67 \%$ and the hardness as $95 \%$.

\section{SELF-HEALING COMPOSITES}

Self-healing composites have become an increasingly important subject of research since the early 1980s, as they make it possible to ensure the safety of building components that are loaded or exposed to various stresses by repairing the damage that occurs in polymer-based composites (Brown 2011).

Self-repairing smart materials are developed by taking inspiration from biological systems such as repair of bleeding areas through vessels. Polymers and polymer-based structural composites are highly susceptible to damage caused by mechanical, chemical, thermal, UV radiation, or a combination of these factors, and can undergo various damages under these effects. This may lead to the formation of deep micro cracks in the structure where detection and external intervention is difficult or impossible. The presence of microcracks in the polymer matrix can affect the dominant properties of both the fiber and matrix of a composite (Wu et al. 2008).

Depending on the active substance placed in the matrix during the production phase of the composite, the time and conditions for the material to self-repair in case of damage vary. The beginning of the repair process can take two forms. One is that the active substance starts with external intervention such as exposure to heat, light, mechanical action and chemicals. The other can be autonomously, without any external effects, by breaking the microcapsule containing the restorative agent as the crack progresses (Algaifi etal. 2021). The classification of the self-healing process of materials according to external effect is shown in Figure 5.

\subsection{Autonomous Healing}

Self-repair of a material whose internal structure is damaged is a common situation in nature. As an imitation of the system in nature, the self-repair of composite materials can be achieved with micro capsules or micro veins placed in them. (Cao et al. 2020).

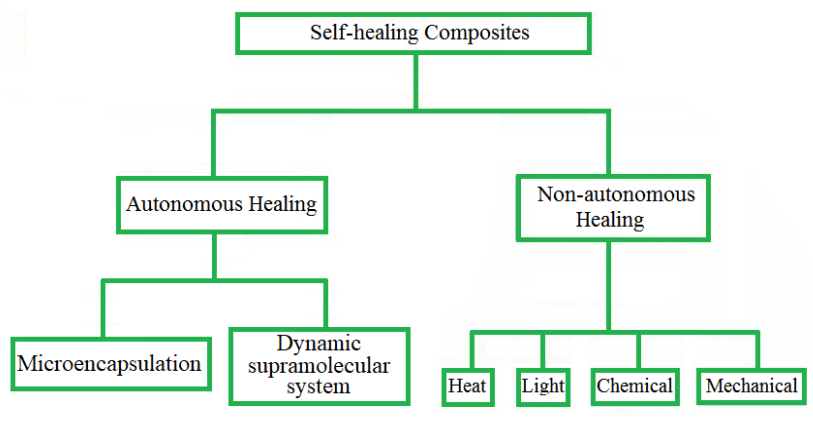

Figure 5. Classification of self-healing processes

\subsubsection{Microencapsulation}

In autonomous repair, microcapsules break down with the effect of breaking and the active substance inside penetrates into capillary cracks. The material interacts with the catalyst embedded in the matrix and the polymerization process takes place. Thus, the autonomous self-repair process of the damaged material begins (Pittala 2021). The autonomous self-healing process of damaged composite materials is shown schematically in Figure 6.

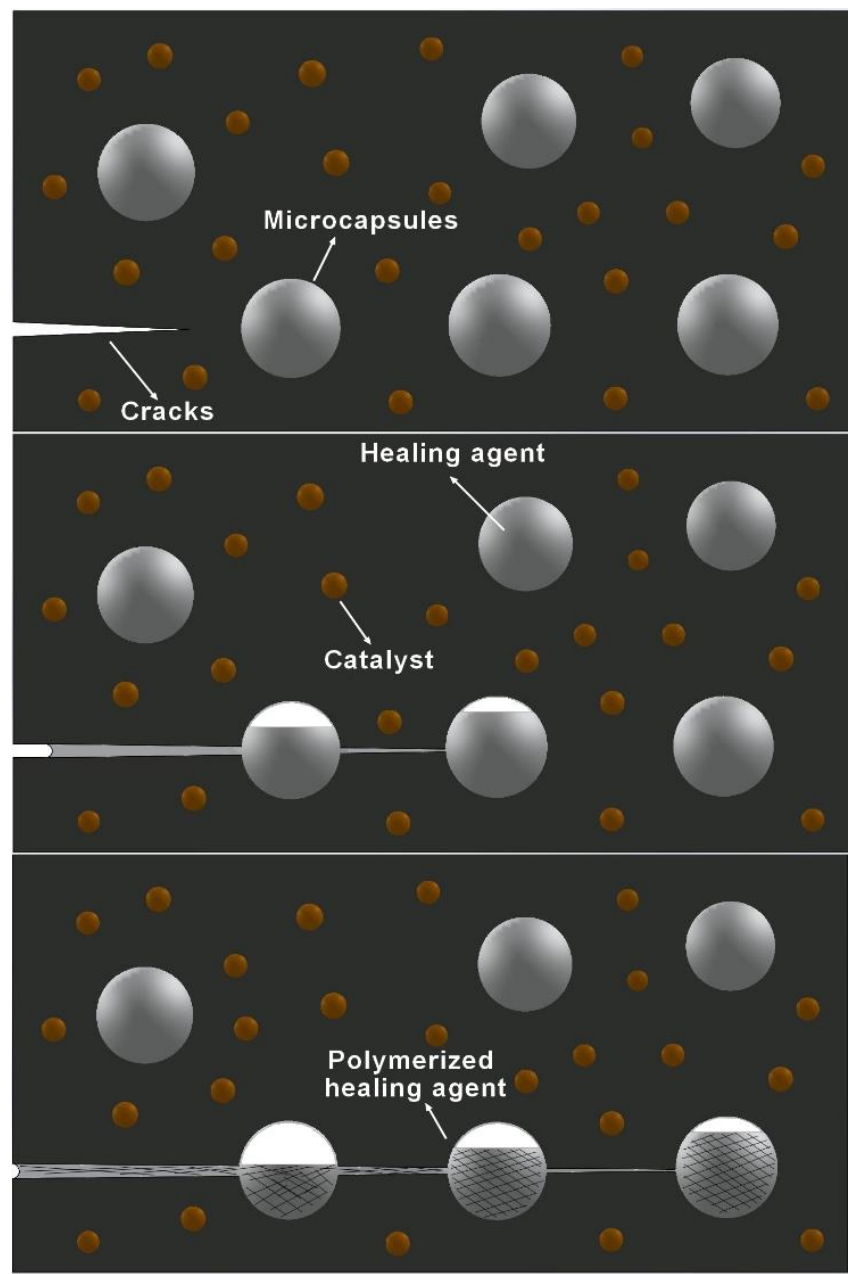

Figure 6. Schematic representation of the autonomous self-repair method 


\subsubsection{Dynamic supramolecular system}

With the dynamic supramolecular system, its selfhealing takes place by combining two different types of polymers with a macro-scale interface interaction. The basic concept of this self-healing variant is based on cross-linking processes that enable the repair of mechanically induced damage with subsequent networking (Zheng et al. 2021). The self-healing mechanism realized with the dynamic supramolecular system is shown in Figure 7.
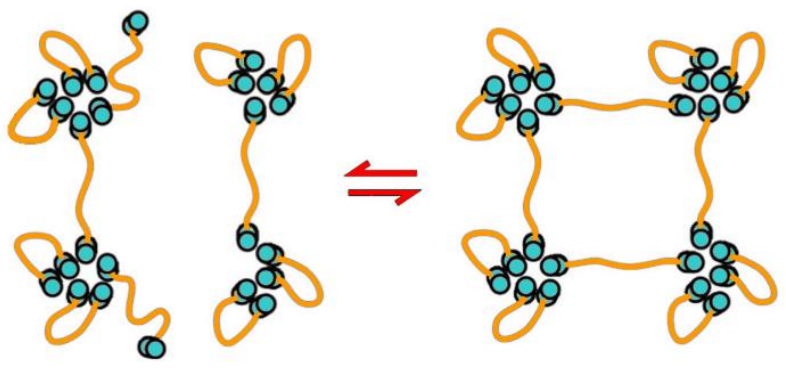

Figure 7. Dynamic supramolecular system

\subsection{Non-autonomous healing}

An external trigger is needed for the nonautonomous healing process to begin. This trigger can be heat, light, mechanical force, or a chemical.

\subsubsection{Heat}

Heat is the trigger currently used in most self-healing composite materials. Most of the studies on self-healing materials in the literature use heat as a trigger [Fang et al. 2017; Wu et al. 2018; Le et al. 2017]. Compared to other non-autonomic self-healing systems, these mechanisms are most applicable to polymer matrix composites due to their relatively easy thermal control.

\subsubsection{Light}

Light can be used in the initiation of the chemicalbased improvement process due to the rapidity of photo reactions. Using light as a trigger provides the advantage of choosing the most suitable wavelength (visible light or UV light) for the material. Since the light can also be placed in the desired area, it provides more control of local damage during the healing process. There are studies in the literature that use light as a trigger in selfhealing materials. [Amamoto et al., 2011; Telitel et al. 2014; Meng et al. 2016; Michal et al. 2013].

\subsubsection{Mechanical}

Biological systems can actively and functionally respond to mechanical triggers. However, in polymers, in case of mechanical loading, the covalent bonds of material can break. This causes the material to be damaged. Intelligent molecular design developed as an alternative to bulk polymers has a positive effect on the mechanical force applied to synthetic materials [Liu et al.
2015; Piermattei et al. 2009; Watuthanthrige et al. 2020]. When these materials are damaged, thanks to the mechanophore compounds placed in them, they can repair themselves with a triggering force. Depending on the direction of the force, covalent bonds can be broken and reattached.

\subsubsection{Chemical}

Another trigger used in self-healing composite materials is chemical triggers. Chemical triggers activate the self-healing system by providing the appropriate conditions such as increasing the $\mathrm{pH}$ value or decreasing the chloride ion concentration. When the appropriate conditions are met, the healing agent is released from microcapsules and the healing process begins. There are studies in the literature on self-healing composite materials activated by chemical triggers [Wang et al. 2018; Yang and Urban 2018; Li et al. 2018].

\subsection{Experimental Studies on Self-healing Composites}

Various studies have been done on self-healing composite materials in the literature. The efficiency of the method was observed by comparing the results of the tests applied to the samples that were not damaged and the self-healed samples.

Everitt et al. (2015) added carboxyl-finite liquid butadiene-acrylonitrile as a healing microcapsule to glass fiber reinforced epoxy matrix composite plates. They subjected the samples to fracture and release tests. As a result of the study, they observed that the selfhealing samples showed an improvement of $139 \%$ and $269 \%$ in shear strength and fracture toughness, respectively, compared to the non-damaged samples.

He et al. (2019) added microcapsules with isocyanate active ingredient to epoxy and polyurethane resins. They subjected the samples to the fracture toughness test. They observed that the fracture toughness values of selfhealing samples increased by $105 \%$ compared to undamaged samples.

Do Nascimento et al. (2020) in their study, they added poly (ethylene-co-methacrylic acid) (EMAA) to carbonepoxy composites as a self-healing agent. Dynamic mechanical analysis and interlayer shear strength test were applied to the unmodified sample and the samples with added EMAA. As a result of the study, they observed that the addition of EMAA to carbon epoxy composites prevented visible delaminations in the materials after damage, and increased the interlayer shear strength and storage modulus.

Feng et al. (2020) placed healing agents and fluorescent secret curing agents (FLCA) into epoxy resin in their study. They investigated the self-healing of polymer composites that were damaged underwater. The optimum microcapsule content of the epoxy resin was determined as $15 \%$ and the optimum FLCA content as $6 \%$. They also conducted experiments at different temperatures and times. When the material was damaged by an external force, it could be repaired 
underwater at $60{ }^{\circ} \mathrm{C}$ for 4 hours, and the self-healing efficiency reached $85.6 \%$.

In their study, Ebrahimnezhad-Khaljiri and EslamiFarsani (2020) added 3 different microcapsules, 7\%, $14 \%$ and $21 \%$, into the glass fiber-epoxy composite. They applied tensile and interlayer shear strength (ILSS) tests to the samples. The damaged samples were placed in the oven and kept at $130 \mathrm{C}$ for 60 minutes for the healing process. They then applied the tensile and ILSS tests to the samples a second time. As a result of the study, they observed the self-healing rate of samples in terms of tensile and ILSS strengths as $97 \%$ and $144 \%$, respectively.

In their study, Kumar et al. (2020) placed healing agents into the hybrid resin (vinyl ester / epoxy) composite samples produced by vacuum assisted resin transfer molding (VARTM) method. They applied a low speed impact test to the samples. As a result of the experiments, they reported that the impact resistance of the samples reinforced with healing agents was $177 \%$ higher than the pure samples.
In their study, Wertz et al. (2014) performed a break test on polylactic acid samples in which microcapsules were placed. As a result of the study, they observed that samples kept at room temperature for 24 hours after being damaged regained fracture toughness by $84 \%$ compared to virgin samples.

\subsection{Self-healing efficiency of composites}

Self-healing efficiency is defined as the ability of the material to regain fracture toughness after the fracture test (Aïssa et al. 2012). The fracture test is applied to the sample gradually, ensuring that the sample is damaged in a controlled manner. The crack in the sample is then allowed to close and heal at room temperature. After this healing process, the same sample is retested to measure the healing efficiency and to determine its ability to regain fracture toughness. The healing efficiency results of the previous studies in the literature are gathered together in Table 1.

Table 1. Self-repair efficiency results of studies in the literature

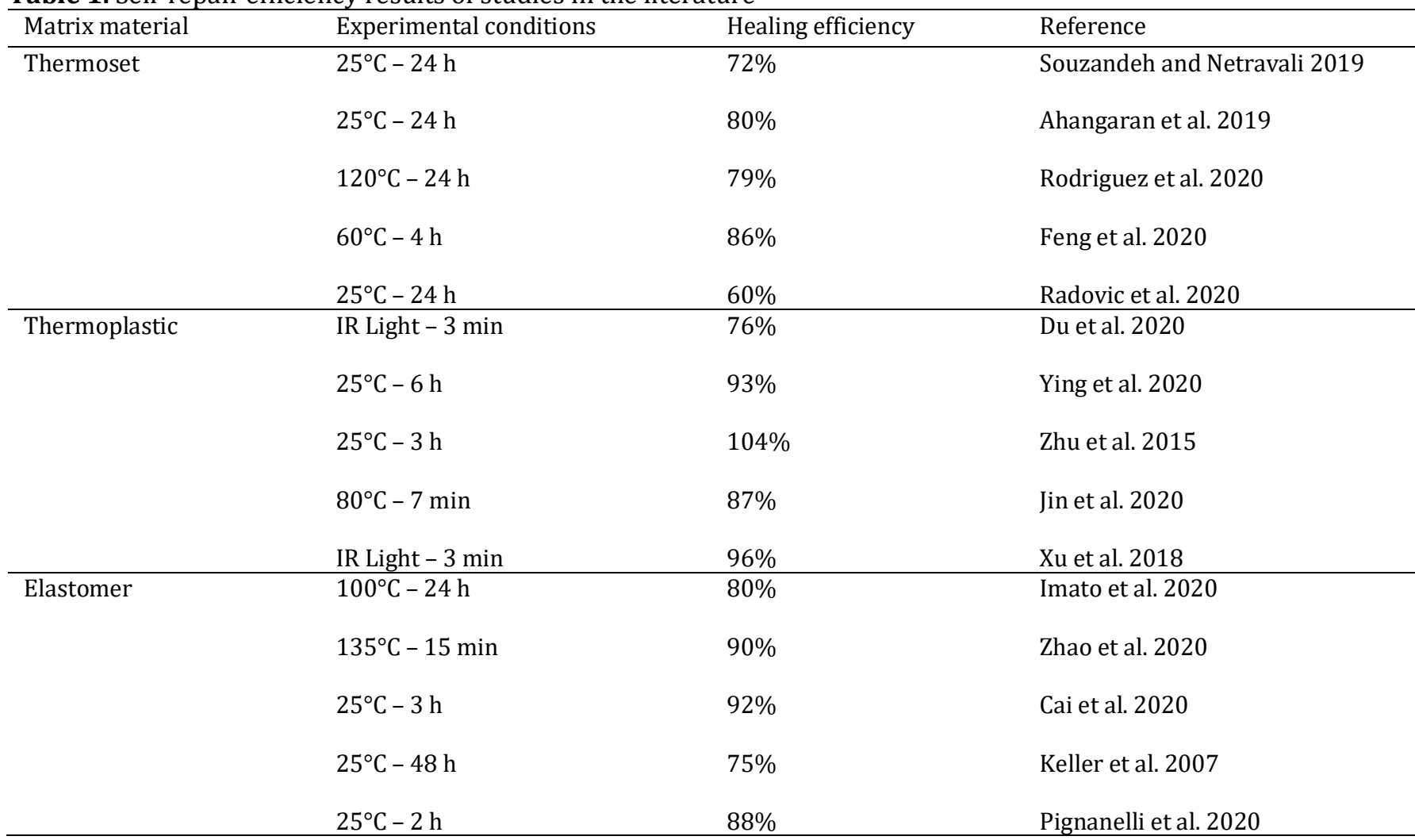

\section{CONCLUSION}

In this study, information has been given by researching the repair of composite materials damaged by various stresses and loads. Self-healing composite materials, which are a type of material developed to repair composites with adhesive bonded patches and to repair themselves when damaged, have been investigated. As a result of the study, it was concluded that both the adhesive bonding method of repair and producing the material as a self-repairing smart material from the very beginning would be much more advantageous in terms of both cost and time compared to replacing parts.

\section{Author contributions}

Yusuf KEPIR: Conceptualization; Investigation; Resources; Manuscript writing; Review \& editing. Alper GÜNÖZ: Investigation; Methodology; Visualization; Manuscript writing. Memduh KARA: Supervision; Validation; Review \& editing.

Conflict of Interest: The authors have no conflicts of interest to declare. 


\section{REFERENCES}

Abrate S (1998). The Dynamics of Impact on Composite Structure, Impact Response and Dynamic Failure of Composites and Laminate Materials, Part 2, editors JK Kim and T., X., Yu. Trans Tech Publications, Switzerland.

Adin H (2018). Numerical analysis of bending behavior of elliptical perforated aluminum plates repaired with composite patch. DÜMF Journal of Engineering 9(2), 713-725.

Ahangaran F, Hayaty M, Navarchian A H, Pei Y \& Picchioni F (2019). Development of self-healing epoxy composites via incorporation of microencapsulated epoxy and mercaptan in poly (methyl methacrylate) shell. Polymer Testing, 73, 395-403.

Aïssa B, Therriault D, Haddad E \& Jamroz W (2012). Self-healing materials systems: overview of major approaches and recent developed technologies. Advances in Materials Science and Engineering, 2012.

Algaifi H A, Bakar S A, Alyousef R, Sam A R M, Ibrahim M W, Shahidan S, ... \& Salami B A (2021). Bio-inspired self-healing of concrete cracks using new B. pseudomycoides species. Journal of Materials Research and Technology.

Amamoto Y, Kamada J, Otsuka H, Takahara A \& Matyjaszewski K (2011). Repeatable photoinduced self-healing of covalently cross-linked polymers through reshuffling of trithiocarbonate units. Angewandte Chemie, 123(7), 1698-1701.

Brown E N (2011). Use of the tapered double-cantilever beam geometry for fracture toughness measurements and its application to the quantification of self-healing. The Journal of Strain Analysis for Engineering Design, 46(3), 167-186.

Cai Y, Zou H, Zhou S, Chen Y \& Liang M (2020). RoomTemperature Self-Healing Ablative Composites via Dynamic Covalent Bonds for High-Performance Applications. ACS Applied Polymer Materials, 2(9), 3977-3987.

Cao S, Zhu W \& Liu T (2020). Bio-inspired self-healing polymer foams with bilayered capsule systems. Composites Science and Technology, 195, 108189.

Dağdelen $O$ (2010). Repair optimization for damaged composite plates. Doctoral dissertation, DEÜ Institute of science, İzmir (in Turkish).

Do Nascimento A A, Fernandez F, da Silva F S, Ferreira E P, Melo J D D \& Barbosa A P C (2020). Addition of poly (ethylene-co-methacrylic acid) (EMAA) as selfhealing agent to carbon-epoxy composites. Composites Part A: Applied Science and Manufacturing, 137, 106016.

Du W, Jin Y, Lai S, Shi L, Shen Y \& Yang H (2020). Multifunctional light-responsive graphene-based polyurethane composites with shape memory, selfhealing, and flame retardancy properties. Composites Part A: Applied Science and Manufacturing, 128, 105686.

Ebrahimnezhad-Khaljiri H \& Eslami-Farsani R (2020). The tensile properties and interlaminar shear strength of microcapsules-glass fibers/epoxy self- healable composites. Engineering Fracture Mechanics, 106937.

Erkek B (2019). Investigation of the effects of thermal aging on the buckling behavior of composite boards repaired using patches and adhesives. Master's Thesis, Dicle University Institute of Science, Diyarbakır (in Turkish).

Everitt D T, Luterbacher R, Coope T S, Trask R S, Wass D F \& Bond I P (2015). Optimisation of epoxy blends for use in extrinsic self-healing fibre-reinforced composites. Polymer, 69, 283-292.

Fang Y, Du X, Du Z, Wang H \& Cheng X (2017). Light-and heat-triggered polyurethane based on dihydroxyl anthracene derivatives for self-healing applications. Journal of Materials Chemistry A, 5(17), 8010-8017.

Feng H, Yu F, Zhou Y, Li M, Xiao L \& Ao Y (2020). Fabrication of microcapsule-type composites with the capability of underwater self-healing and damage visualization. RSC Advances, 10(56), 3367533682.

He Y, Liu X \& Yu Z (2019). Mechanical properties of UVcurable carbon fiber-reinforced polymer composite patch: Repair evaluation of damaged aluminum alloy. Polymers for Advanced Technologies, 30(8), 2034-2044.

He Z, Jiang S, An N, Li X, Li Q, Wang J, ... \& Kang M (2019). Self-healing isocyanate microcapsules for efficient restoration of fracture damage of polyurethane and epoxy resins. Journal of Materials Science, 54(11), 8262-8275.

Imato K, Nakajima H, Yamanaka R \& Takeda N (2020). Self-healing polyurethane elastomers based on charge-transfer interactions for biomedical applications. Polymer Journal, 1-8.

Jin C, Sinawang G, Osaki M, Zheng Y, Yamaguchi $H$, Harada A \& Takashima Y (2020). Self-healing thermoplastic polyurethane linked via host-guest interactions. Polymers, 12(6), 1393.

Kara M (2012). Damage behavior under internal pressure of filament wound GRP pipes repaired with patch after low speed impact. Doctoral Thesis, Selçuk University Institute of Science, Konya (in Turkish)

Keller M W, White S R \& Sottos N R (2007). A selfhealing poly (dimethyl siloxane) elastomer. Advanced Functional Materials, 17(14), 2399-2404.

Kilinc İ M (2019). Experimental investigation of bonding parameters in aluminum foam sandwich structures. Master's thesis, Bursa Uludağ University Institute of Science, Bursa (in Turkish).

Kim S, Ha J, Yoon S \& Kim M (2020). A study on mechanical properties after bonded repair of sandwich composite materials. Modern Physics Letters B, 34(07n09), 2040033.

Kumar R, Hynes N R J, Saravanakumar S S, Senthamaraikannan P, Khan A, Asiri A M, ... \& Nagarajan S (2020). Concept of self-repair and efficiency measurement in polymer matrix composites. In Self-Healing Composite Materials (pp. 375-391). Woodhead Publishing.

Le H H, Böhme F, Sallat A, Wießner S, auf der Landwehr M, Reuter U, ... \& Das A (2017). Triggering the SelfHealing Properties of Modified Bromobutyl Rubber 
by Intrinsically Electrical Heating. Macromolecular Materials and Engineering, 302(4), 1600385.

Li Z, Davidson-Rozenfeld G, Vázquez-González $M$, Fadeev M, Zhang J, Tian H \& Willner I (2018). Multitriggered supramolecular DNA/bipyridinium dithienylethene hydrogels driven by light, redox, and chemical stimuli for shape-memory and selfhealing applications. Journal of the American Chemical Society, 140(50), 17691-17701.

Li C, Zhao Q, Yuan J, Hou Y \& Tie Y (2019). Simulation and experiment on the effect of patch shape on adhesive repair of composite structures. Journal of Composite Materials, 53(28-30), 4125-4135.

Liu Y, Liu Y, Hu H, Liu Z, Pei X, Yu B, ... \& Zhou F (2015). Mechanically induced self-healing superhydrophobicity. The Journal of Physical Chemistry C, 119(13), 7109-7114.

Meng Y, Yang J C, Lewis C L, Jiang J \& Anthamatten M (2016). Photoinscription of chain anisotropy into polymer networks. Macromolecules, 49(23), 91009107.

Michal B T, Jaye C A, Spencer E J \& Rowan S J (2013). Inherently photohealable and thermal shapememory polydisulfide networks. ACS Macro Letters, 2(8), 694-699.

Moreira R D F, de Moura M F S F, Silva F G A, Ramírez F M G \& Silva F D R (2020). Numerical comparison of several composite bonded repairs under fatigue loading. Composite Structures, 112250.

Piermattei A, Karthikeyan S \& Sijbesma R P (2009). Activating catalysts with mechanical force. Nature chemistry, 1(2), 133-137.

Pignanelli J, Qian Z, Gu X, Ahamed M J \& Rondeau-Gagné $S$ (2020). Modulating the thermomechanical properties and self-healing efficiency of siloxanebased soft polymers through metal-ligand coordination. New Journal of Chemistry, 44(21), 8977-8985.

Pittala R K (2021). Effect of epoxy resin healing agent viscosity on the self-healing performance of capsules reinforced polymer composite. Journal of Polymer Research, 28(4), 1-19.

Psarras S, Loutas T, Galanopoulos G, Karamadoukis G, Sotiriadis G \& Kostopoulos V (2020). Evaluating experimentally and numerically different scarfrepair methodologies of composite structures. International Journal of Adhesion and Adhesives, 97, 102495.

Radovic I, Stajcic A, Radisavljevic A, Veljkovic F, Cebela M, Mitic V V \& Radojevic V (2020). Solvent effects on structural changes in self-healing epoxy composites. Materials Chemistry and Physics, 256, 123761.

Rodriguez R, Bekas D G, Flórez S, Kosarli M \& Paipetis A $S$ (2020). Development of self-contained microcapsules for optimised catalyst position in self-healing materials. Polymer, 187, 122084.

Souzandeh H \& Netravali A N (2019). Self-healing of 'green'thermoset zein resins with irregular shaped waxy maize starch-based/poly (D, L-lactic-co- glycolic acid) microcapsules. Composites Science and Technology, 183, 107831.

Telitel S, Amamoto Y, Poly J, Morlet-Savary F, Soppera O, Lalevée J \& Matyjaszewski K (2014). Introduction of self-healing properties into covalent polymer networks via the photodissociation of alkoxyamine junctions. Polymer Chemistry, 5(3), 921-930.

Wang C, Fadeev M, Zhang J, Vázquez-González M, Davidson-Rozenfeld G, Tian H \& Willner I (2018). Shape-memory and self-healing functions of DNAbased carboxymethyl cellulose hydrogels driven by chemical or light triggers. Chemical science, 9(35), 7145-7152.

Watuthanthrige N D A, Ahammed B, Dolan M T, Fang Q, Wu J, Sparks J L, ... \& Ye Z (2020). Accelerating dynamic exchange and self-healing using mechanical forces in crosslinked polymers. Materials Horizons, 7(6), 1581-1587.

Wertz J T, Mauldin T C \& Boday D J (2014). Polylactic acid with improved heat deflection temperatures and self-healing properties for durable goods applications. ACS applied materials \& interfaces, 6(21), 18511-18516.

Wu D Y, Meure S \& Solomon D (2008). Self-healing polymeric materials: a review of recent developments. Progress in polymer science, 33(5), 479-522.

Wu X, Li J, Li G, Ling L, Zhang G, Sun R \& Wong C P (2018). Heat-triggered poly (siloxane-urethane) $s$ based on disulfide bonds for self-healing application. Journal of Applied Polymer Science, 135(31), 46532.

Xu X, Fan P, Ren J, Cheng Y, Ren J, Zhao J \& Song R (2018). Self-healing thermoplastic polyurethane (TPU)/polycaprolactone (PCL)/multi-wall carbon nanotubes (MWCNTs) blend as shape-memory composites. Composites Science and Technology, $168,255-262$.

Yang Y \& Urban M W (2018). Self-healing of polymers via supramolecular chemistry. Advanced Materials Interfaces, 5(17), 1800384.

Ying W B, Yu Z, Kim D H, Lee K J, Hu H, Liu Y, ... \& Zhu J (2020). Waterproof, Highly Tough, and Fast SelfHealing Polyurethane for Durable Electronic Skin. ACS Applied Materials \& Interfaces, 12(9), 1107211083.

Zhao L, Shi X, Yin Y, Jiang B \& Huang Y (2020). A selfhealing silicone/BN composite with efficient healing property and improved thermal conductivities. Composites Science and Technology, 186, 107919.

Zheng N, Xu Y, Zhao Q \& Xie T (2021). Dynamic Covalent Polymer Networks: A Molecular Platform for Designing Functions beyond Chemical Recycling and Self-Healing. Chemical Reviews, 121(3), 1716-1745.

Zhu D Y, Cao G S, Qiu W L, Rong M Z \& Zhang M Q (2015). Self-healing polyvinyl chloride (PVC) based on microencapsulated nucleophilic thiol-click chemistry. Polymer, 69, 1-9. 